\title{
La Apoteosis de Hércules: un discurso humanista en la Sevilla del Renacimiento
}

The Apotheosis of Hercules: a humanist discourse in the Seville of the Renaissance

Juan José Castillo Herrera

${ }^{1}$ Graduado en Historia del Arte, Universidad de Málaga, España (castillo.herrera.juanjo@gmail.com)

Recibido el 29 de enero de 2017; revisado el 15 de marzo de 2017; aceptado el 23 de abril de 2017; publicado el 1 de julio de 2017

RESUMEN: El presente trabajo versa sobre la plasmación de las ideas humanistas del Renacimiento italiano de la $2^{\mathrm{a}}$ mitad del s. XV en la pintura sevillana de los ss. XVI y XVII. El discurso se articula en base a una serie de reflexiones sobre cómo el pensamiento neoplatónico de los humanistas italianos quedó plasmado en las formas artísticas italianas, europeas y españolas y, en particular, en la obra de Francisco Pacheco, en concreto, sus pinturas en la "Casa de Pilatos" de Sevilla: La Apoteosis de Hércules. A través del estudio iconográfico y la interpretación de su discurso iconológico se establecen concordancias entre el pensamiento humanista y los principios del cristianismo con el fin de transmitir un mensaje moralizante.

PALABRAS CLAVE: Neoplatonismo, Renacimiento, Humanismo cristiano, Francisco Pacheco, Apoteosis de Hércules, Neoestoicismo.

\begin{abstract}
The currently study relates the different translations of the humanist Renaissanceideas of the 2nd half of 16th Century, from Italy to Seville's painting school of 16th \& 17th Centuries, specifically the Academy of Francisco Pacheco del Río. The speech is based in some ideas on how the neoplatonic thoughts of the first Italian humanists, were reflected on Italian, European and Spanish art forms and, in particular, the work of the mentioned painter and his paintings at the "House of Pilatos" in Seville: The Apotheosis of Hercules. Through the iconographic study and interpretation of his iconological speech, concordances between humanist ideas and the principles of Christianism are established in order to convey a moralizing message.
\end{abstract}

KEYWORDS: Neoplatonism, Renaissance, Christian Humanism, Francisco Pacheco, Apotheosis of Hercules, Neostoicism. 
Siempre que se aborda el estudio del Renacimiento, llega a la mente el pensamiento humanista de los eruditos neoplatónicos defensores del Neoestoicismo1. Sin embargo, por la actual organización de los planes docentes, pocas son las ocasiones en que es posible estudiar aquellas tesis. En las sesiones académicas sobre Arte del Renacimiento, continuamente se nombra a los fundadores de esta corriente, pero son contadas las ocasiones en que se llega a conocer su pensamiento.

Es por ello por lo que acometo el estudio de una figura esencial en la historia del arte español: Francisco Pacheco del Río. Pintor y tratadista, dedicado básicamente a pintura religiosa, ostentó el cargo de veedor de la Inquisición, pero de forma excepcional recibió el encargo de realizar una obra de tema pagano, La Apoteosis de Hércules. En esta obra representa episodios y personajes mitológicos para transmitir un complejo discurso iconológico que, a su vez, refleja principios moralizantes propios del cristianismo.

Durante mis estudios de Grado en Historia del Arte, hubo una de serie de intervenciones de profesores y especialistas que me animaron a realizar una investigación de este tipo, y, por ello, busqué programas en los que se conciliaran los mensajes de la mitología con el pensamiento cristiano. A continuación cito algunas de estas intervenciones:

1. “(...) A finales de la Edad Media, y durante toda la Edad Moderna, es muy habitual encontrar ciclos y programas iconográficos que asocien los valores morales de las figuras mitológicas con las virtudes cristianas. Así, no es difícil encontrar figuras como la de Hércules asociadas a la figura de Cristo, o la de los dioses olímpicos a santos y personajes bíblicos". (Dra. Reyes Escalera, asignatura Lenguajes Artísticos y Lecturas de la Imagen).

2. "Los miembros de la Academia neoplatónica de Marsilio Ficino defendían que el Reino de los Cielos, su disfrute, no sólo estaba reservado a los hebreos, sino también a los vecinos de las naciones paganas, y que con la contemplación de la belleza de los dioses griegos y romanos, podrían llegar a descubrir a Dios". (Dr. Juan María Montijano, asignatura Arte europeo del Renacimiento y del Barroco).

3. "En programas iconográficos de iglesias, sacristías o palacios, es común ver emparejadas representaciones de sibilas de la Antigüedad con los evangelistas, profetas o apóstoles, fruto del intento humanista por sintonizar ambos mundos: el pagano y el cristiano”. (Dr. José Miguel Morales Folgueras, asignatura Arte español del Renacimiento y del Barroco).

Fue por este motivo por lo que me decidí a abordar el tema que intentaré exponer a continuación.

\footnotetext{
${ }^{1}$ Movimiento filosófico fundado por el humanista flamenco Justo Lipsio (1547-1606) quien, durante el s. XVI, desarrollaría sus teorías en diversos tratados. El neoestoicismo sostiene que el ser humano no debe ceder ante la pasión terrenal, sino someterse a Dios, distinguiendo cuatro "pasiones estoicas": gula, alegría, miedo y dolor. El neoestoicismo tuvo mucha influencia en escritores, artistas y eruditos de los siglos XVI-XVIII, dejando reflejo de esta corriente en sus obras.
} 


\section{El Humanismo en la Italia Renacentista: Marsilio Ficino, la 'Theologia Platonica' y la Academia de Florencia}

"La 'prisca theologia platonica' encaja muy bien dentro del pensamiento cristiano" (Santidrián, 2007:60)

Con esta sencilla frase se podría sintetizar el conjunto de las tesis humanistas formuladas por Marsilio Ficino, Pico della Mirandola y Angelo Poliziano. Estos intelectuales componen el más notable grupo del mundo humanista de la Florencia del Renacimiento, ciudad foco del humanismo que irradiará al resto de Europa.

Marsilio Ficino (1433-1499), rescata las tesis platónicas e intenta armonizarlas con el pensamiento cristiano. En sus comentarios al Fedroz afirma que, tanto Platón como San Pedro o San Pablo, coinciden cuando hablan del único amor, "el amor de la belleza absoluta que es Dios", porque Dios es "la Belleza absoluta y el Bien absoluto".

Pico della Mirandola (1463-1494) se nutrió de las fuentes de la sabiduría griega, oriental, árabe y judía. En su obra principal, la Oratio de dignitate hominis -discurso sobre la dignidad del hombre-, pone al hombre como centro del universo, capaz de escoger entre "degradarse entre los brutos o regenerarse en Dios". Sus postulados son: la moral, que domina y purifica al hombre; la filosofía, que lo libera, y la teología, que le acerca a Dios. Todo esto sólo es posible en la paz y por la paz.

Angelo Poliziano (1454-1494), en su obra Lamia, "La bruja", establece que la belleza proviene de los números, orden y proporciones, y que la ciencia que se ocupa de las cosas bellas y del origen de todo, es la filosofía. El filósofo debe rechazar la avaricia, el hurgar en la vida de los demás o ver sólo los defectos ajenos, vicios igualmente condenados por las Sagradas Escrituras. Alude a la fábula de Esopo cuando dice que cada hombre lleva dos alforjas, una al pecho conteniendo los defectos ajenos, y otra a la espalda que contiene los propios, y que es conveniente dar la vuelta a las alforjas para poder verse los defectos de forma conveniente.

De estas tres tesis, por tanto, se desprende básicamente la mayor parte del pensamiento, ideario y filosofía del Humanismo Cristiano Renacentista en Italia.

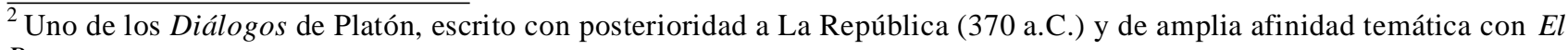
Banquete.
} 


\section{El Humanismo en España: Sevilla y la academia de Francisco Pacheco}

Con el cambio de época y, con la llegada de la modernidad, surge el Renacimiento en toda Europa. Fruto de las nuevas ideas, durante la Edad Moderna, los promotores de las nuevas obras van a ser la Corona y las grandes familias de la nobleza. Nobles y aristócratas se van a fijar en los modelos italianos, encargando programas humanistas tales como programas astrológicos, o también alegorías del triunfo de la virtud sobre los vicios, temas mitológicos, etc.

Sevilla recibe fuertes influencias por haberse convertido en Puerto de América. Desde allí parten los barcos hacia el Nuevo Mundo, e igualmente, desde Italia, llegan las nuevas ideas a la ciudad. La riqueza originada por este tráfico revierte en la promoción de edificios, a los que llegarán artistas italianos para su decoración. Sevilla será, por tanto, la gran urbe por la que entrarán las nuevas ideas humanistas a España.

\section{Francisco Pacheco del Río, los humanistas y la Academia}

Suegro y maestro de Velázquez, a Pacheco también se le conoce como tratadista. Su tratado más conocido es El Arte de la Pintura, 1649. La Academia que "heredó" Pacheco seguía el modelo de las italianas, herederas del espíritu de la de M. Ficino, donde estudiosos y humanistas se reunían informalmente, en clima de amistad, para discutir sobre asuntos de interés común.

A mediados del s. XVI el estudioso y poeta don Juan de Mal Lara abrió su Estudio, una pequeña escuela formadora de niños en humanidades y estudio de los clásicos. Mal Lara se centró en el estudio de la Antigüedad y la religión. En 1571, en la academia se encontraba el canónigo Pacheco, quien colocó a su sobrino Francisco en la misma como aprendiz de pintor. A su muerte, Pacheco "hereda" la academia.

Un amigo de Pacheco -entre otros- fue don Fernando Enríquez Afán de Ribera, tercer duque de Alcalá, quien enriqueció su palacete, la Casa de Pilatos, con antigüedades traídas desde Nápoles. Con una cuidada educación, demostró gran afición por las humanidades. Formó una gran colección de pinturas y obras de arte, y reunió una gran biblioteca, cuyo techo fue decorado con las pinturas de su amigo Pacheco.

Pacheco, tanto su Arte de la Pintura como su obra pictórica se basan por completo en fuentes italianas. Ahora bien, su rigidez eclesiástica es patente, aun cuando el realismo de su obra es 
indiscutible (Schlosser, 1976: 544). Sin embargo, su pintura no llegó a alcanzar el nivel que podría esperarse. Las pinturas de Pacheco se presentan con un estilo algo frío y poco naturalista, pero demuestra gran maestría a la hora de presentar las figuras, muy rotundas, esculturales, convirtiéndose en el vehículo perfecto para transmitir mensajes morales. La ortodoxia se convierte en su centro de atención. Pacheco fue veedor de pinturas sagradas del Tribunal de la Inquisición y estableció fórmulas para que las obras sirviesen para "estimular adecuadamente a los fieles para que (...) pudieran adorar a Dios y cultivar la piedad” (Marías, 1993: 16).

\section{El Palacio de los Adelantados Mayores de Sevilla: la Casa de Pilatos}

La Casa de Pilatos, en los documentos de época, es citada como "Casas Principales del Duque de Alcalá de la collación de San Esteban". En un documento de 1755 se añade "vulgarmente llamadas Casa de Pilatos" (Lleó Cañal, 1998: 11).

El primer Marqués de Tarifa solía hacer un Vía Crucis que enlazaba la primera estación a la puerta del palacete con la Cruz del Campo. Por ser la primera estación penitencial, episodio en que Cristo es sentenciado y Pilatos se lava las manos, es por lo que comenzó a conocerse como Casa de Pilatos, y también, porque la distancia entre estos dos puntos era similar a la existente entre el Pretorio y el Monte Calvario.

Se trate de mito o leyenda, cierto es que la casa adquirió su esplendor durante el s. XVI y fue el filtro por el que el gusto renacentista entraba en la ciudad. En cuanto a sus jardines, están el 'Jardín chico' y el 'Jardín grande’ [1], concebido al modo de los jardines italianos rodeado por logias. En una gruta hay un estanque y un surtidor sobre los que se dispone la escultura de una Venus dormida3.

\footnotetext{
${ }^{3}$ En opinión del Prof. D. José Miguel Morales Folguera, teniendo en cuenta que la imagen se encuentra en una gruta donde hay un estanque y una fuente, y la imagen no ofrece más atributos, en lugar de Venus, más bien se trata de la ninfa Egeria, o 'Ninfa del álamo negro', diosa de las fuentes y de los partos, que había sido metamorfoseada por Diana en la fuente de su mismo nombre tras la muerte del rey Numa. Es frecuente su representación recostada sobre una fuente o surtidor, dormitando o sollozando, y dentro de una gruta o caverna.
} 


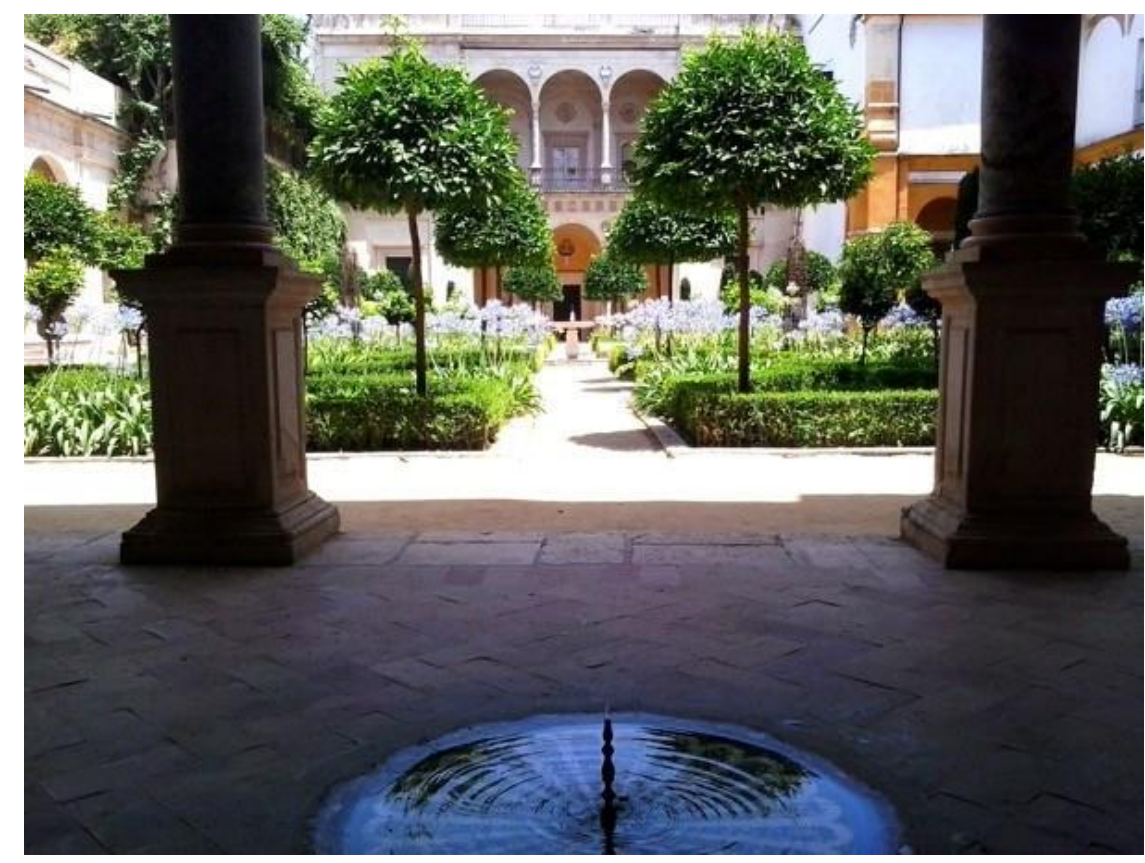

[Fig. 1] Jardín Grande. Fuente: fotografía de autor.

\section{La Apoteosis de Hércules: Techo del Camarín Grande de la Casa de Pilatos, Sevilla}

Hércules es "el héroe que gozó de más favor en el medio renacentista español" (Sebastián, 1978: 197). Muchas de sus hazañas acontecieron en Hesperia, lugar donde Atlas sostenía la bóveda del cielo, y al que Hércules sustituyó para que entrase en el Jardín de las Hespérides y cogiese las manzanas de oro que debía entregar a su primo Euristeo, ya que él mismo, por consejo de Prometeo, no debía entrar en el jardín. Máximo modelo de virtud, hombre virtuoso, fuerte, de buenas costumbres, representa la bondad y fortaleza del alma.

El duque encargó, en 1603, la reforma de las salas altas de la Casa. En el techo de un gran salón de unos 60m2 se instalaron unos lienzos pintados al temple por Pacheco. Se representan "ocho Fabulas, con grutescos, i otros adornos" (Pacheco, 1866: 341), inspirados en obras italianas y modelos de la Antigüedad. Pacheco no aporta explicación sobre la obra e incluso, dada su rigidez eclesiástica, quizá se arrepintiese de realizarla. No obstante, el resultado final es un completo programa representativo del humanismo moderno o neoestoicismo, relacionando paganismo y cristianismo. 


\section{El programa iconográfico}

Las pinturas, fechadas en 1604, representan la Apoteosis de Hércules [2] al Olimpo tras realizar los doce trabajos. Otros seis temas completan el programa: Faetón, Ganimedes, la Justicia, la Envidia, La Caída de Ícaro y Perseo cabalgando sobre Pegaso.

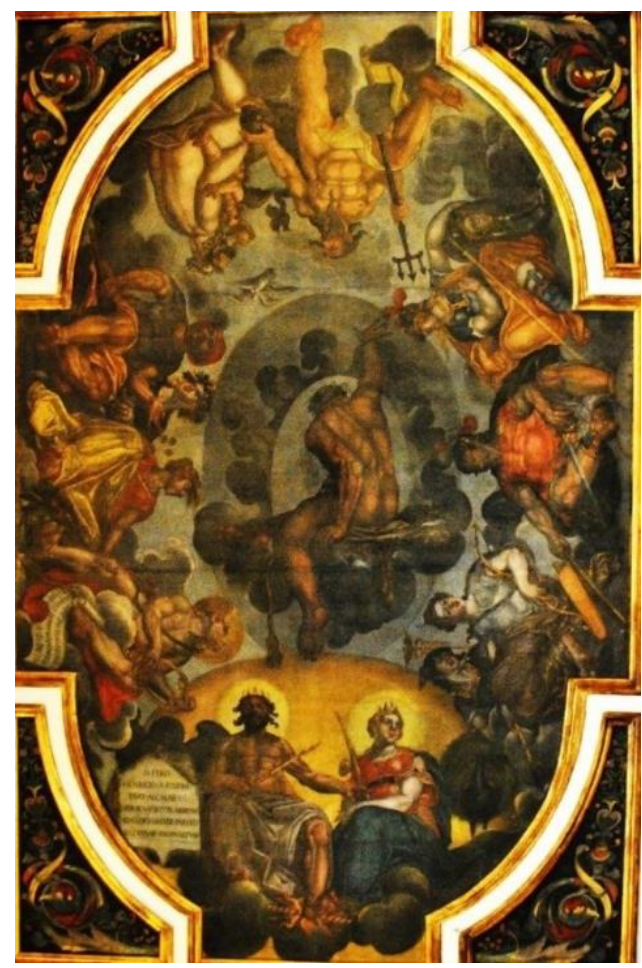

[Fig. 2] Apoteósis de Hércules (1604). Fuente: fotografía de autor.

En el centro, Hércules, desnudo, sentado y de espaldas. Es el único mortal que se sienta entre los dioses, gloria reservada solo a quien supo vencer los vicios. Colocando en el centro al héroe, se representa al joven duque las virtudes que debe adoptar y los vicios que debe eludir. Pero además lo muestra de espaldas, o sea, su naturaleza virtuosa lo hace a la vez un hombre humilde, que conoce y no esconde sus defectos4. Alrededor del héroe identificamos a cada uno de los dioses olímpicos:

-- A los pies Júpiter, en el trono, maduro, barbado, con el águila, en su mano derecha sostiene un cetro. El águila sostiene una cartela con la inscripción 'D. Ferd. Henricio a Ribera Duci Alcalae III...' . Al lado de Júpiter su hermana y esposa Juno, con mirada recelosa y tocada con diadema. Modelo de castidad y protectora de la fidelidad del matrimonio, también sostiene un cetro. A su lado, el pavo real con los cien ojos de Argos para vigilar a Ío, una de las muchas amantes de su esposo.

\footnotetext{
${ }^{4}$ Véase referencias de Angelo Poliziano en Lamia: alusiones a la fábula de Esopo.
} 
-- A la derecha Mercurio, hijo de Júpiter, mensajero de su padre y de los dioses, ataviado con el petaso y el caduceo. Le acompaña Diana, diosa de la caza, de los animales y de los partos, con escudo, aljaba y la media luna sobre su cabeza.

-- En sentido ascendente, Marte, hijo de Júpiter y Juno, dios de la guerra, de la fuerza bruta, ataviado con capa, casco y coraza, portando una espada o lanza, y a su lado Minerva, diosa guerrera, con casco, porta el escudo con la cabeza de Medusa.

-- En la cabecera Neptuno, dios de los mares, anciano, con abundantes barbas, semidesnudo, cabello desgreñado y portando el tridente. A su lado Venus, diosa del amor y la belleza, sentada de espaldas, desnuda, y sosteniendo a Cupido. La paloma, símbolo de la pureza, revolotea sobre ambos.

-- Finalmente, a la izquierda aparece, en primer lugar Vulcano, herrero de los dioses, dios del fuego y la metalurgia, deforme, barbado, con gorro de fragua y martillo en la mano derecha. Tras él se adivina Baco, dios del vino, y junto a éste Ceres, cuarta esposa de Júpiter según Hesíodo, diosa de la agricultura y la abundancia, portando en su mano unas espigas aún cerradas. En último lugar, cerrando el círculo, Febo, dios de la luz, la belleza, la música, la poesía, semidesnudo, con una lira, aureola, y se adivina que lleva una aljaba. De sus pies surge una partitura a modo de filacteria.

Frente a estas glorias hay otras representaciones: un episodio de la historia de Faetón [3] y otro de la de Dédalo e Ícaro:

Faetón, hijo de Helio -el Sol- y de la mortal Clímene. Su padre le dejó conducir el carro del sol por un día, pero los signos del zodíaco le asustaron y perdió el control, abrasando parte del cielo, creando la Vía Láctea, desecando parte de la Tierra y abrasando y tostando a algunos de los habitantes del Ecuador. Júpiter lo fulminó con un rayo y lo hizo caer al río Erídano, de donde sus hermanas las Helíades lo recogieron.

Dédalo personifica al hombre ingenioso. Destacó como escultor y arquitecto. En Creta construyó un laberinto, donde fue encerrado por el rey Minos. Consiguió escapar fabricando unas alas para él y para su hijo Ícaro, fijándolas al cuerpo con cera. Pero Ícaro se elevó orgulloso y el sol derritió la cera, cayendo y ahogándose en el mar. Faetón sería entonces símbolo de la vanidad y, Dédalo e Ícaro, símbolo de la prudencia. 


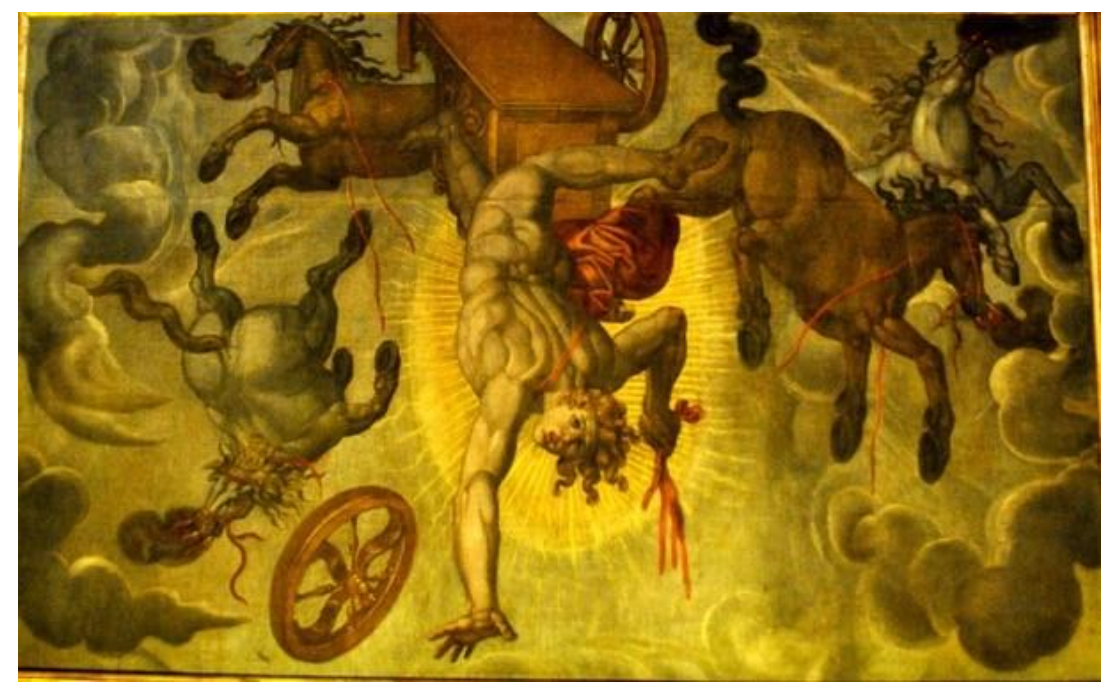

[Fig. 3] La caída de Faetón. Fuente: fotografía de autor.

Encontramos también a Ganimedes y Perseo cabalgando sobre Pegaso [4]. Júpiter se enamoró de Ganimedes y lo raptó un vez que éste se retiró a los bosques a meditar. Lo llevó al Olimpo y lo convirtió en copero real. Perseo, hijo de Dánae, fue concebido cuando Júpiter la sedujo convertido en lluvia de oro. Acrisio, padre de Dánae, recibió un oráculo que le advertía que moriría a manos de su nieto, por lo que los encerró en un arca y los arrojó al mar, llegando a la isla de Sérifos. El rey de la isla prometió dar a su hija en matrimonio y Perseo se comprometió a traer la cabeza de Medusa. Hermes le dio una hoz de acero y las Ninfas le dieron las sandalias voladoras, un casco que lo hacía invisible, y un zurrón para guardar la cabeza. Ganimedes significa, pues, la prudencia, ya que se retiraba a los bosques para que las pasiones mundanas no lo turbasen, y Perseo representaría una virtud más mundana, esto es, la fuerza física, el esfuerzo, el valor, la fama.

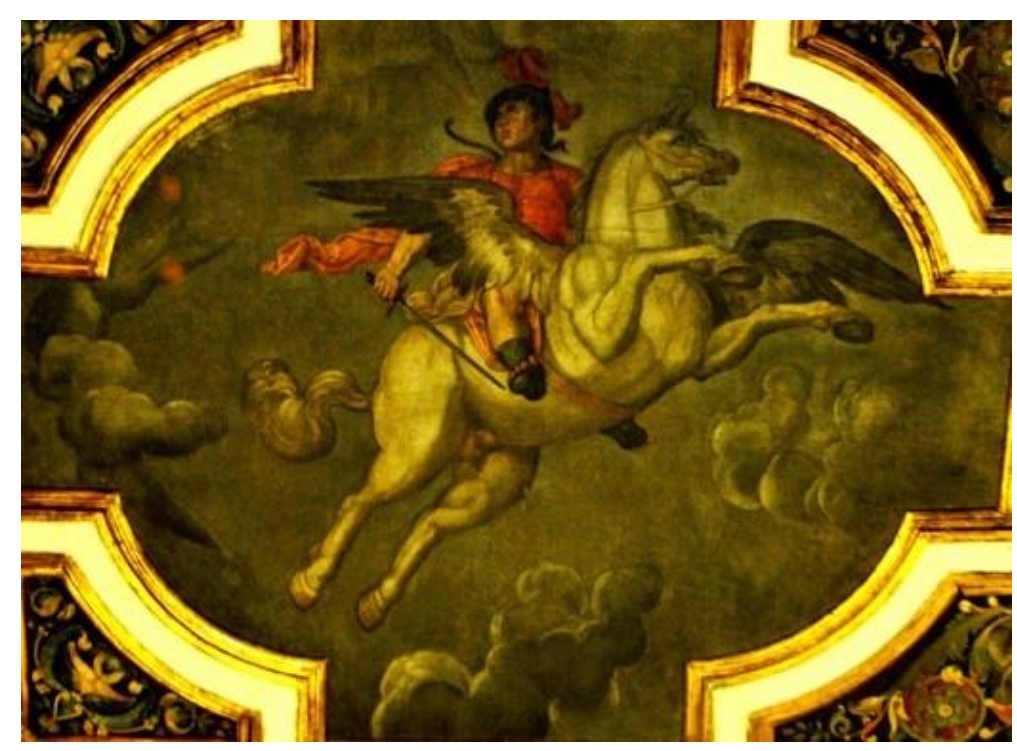

[Fig. 4] Perseo cabalgando sobre Pegaso. Fuente: fotografía de autor. 
Finalmente, otras dos personificaciones: la Justicia y la Envidia [5]. Son la contraposición entre el vicio y la virtud. Astrea, diosa de la Justicia, aparece con sus atributos convencionales: la espada y la balanza (Carmona, 2010: 104). La Envidia se presenta al modo de los emblemas de Alciato: anciana, con pechos caídos, semidesnuda, y alas que le dan cierto aire siniestro (Sebastián, 1993: 106-107), con un zurrón y cabellos desgreñados. Si la Justicia es gozar de la felicidad de dar a cada uno lo suyo y ser la suma de las virtudes, la Envidia sería sufrir por no gozar de los bienes ajenos, raíz de todos los vicios. Se invita al duque a huir de este vicio.

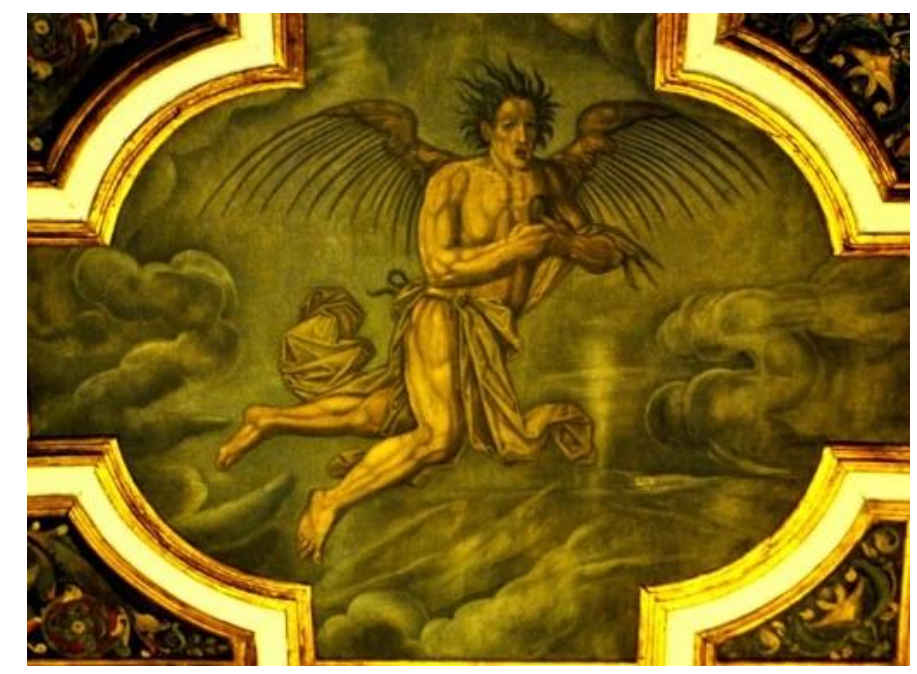

[Fig. 5] La envidia. Fuente: fotografía de autor.

\section{Discurso iconológico}

El programa refleja las virtudes que el duque debe imitar y los vicios que debe eludir. La idea aparece bastante clara: Hércules es el modelo de exemplum virtutis para un joven que, recién cumplida la mayoría de edad, debía enfrentarse a situaciones difíciles. Pero el héroe de Pacheco no es el musculoso, forzudo y terrible que generalmente presentan las fuentes antiguas, sino que aparece como filósofo, austero, contenido, estoico, capaz de dominarse.

El incidir en esta idea de la figura de un Hércules "salvaje" pero domado por la filosofía e insistir en el estudio de las 'cosas elevadas', resultó muy apropiado, ya que el Camarín es paso obligadopara acceder a la biblioteca del palacio. 


\section{Conclusiones}

Podemos decir que se trata de un programa clave en la Historia del Arte español. Obra intelectualizada, en la que se aprecia la fuerte influencia italiana. De no ser por el círculo humanista sevillano, la Academia, ni hubiese existido ni tampoco se habría realizado un programa iconográfico de estas características.

Pacheco conoce las fuentes antiguas, la mitología y la emblemática. Los personajes los identifica con sus atributos y poses. Al presentar la dualidad virtud vs. vicio, enfatiza su discurso con estereotipos como belleza vs. fealdad, dando valores de belleza a las virtudes y caracteres siniestros para los vicios. En los esquemas compositivos sigue el modelo clásico: orden, simetría, proporciones, importancia del dibujo, equilibrio..., conceptos mencionados por Pacheco en su Arte. No obstante, se aprecia cierta rigidez.

En la Sevilla del siglo XVII se filtraron con cuidado los temas mitológicos. Para que se pudiesen representar estos temas, debían expresar valores morales, y nunca romper el equilibrio entre su atractivo y el decoro.

Pintor realista, si bien poco naturalista, muestra obsesión por el dibujo y dota de gran teatralidad a las escenas. Su academicismo hace que su pintura resulte fría, reseca, pero dota a las figuras de carácter eterno, convirtiéndose en modelos a imitar, aunque adolezcan de la grazia vasariana. Defiende la idealización en el arte. Artista retardatario en relación a los pintores del s. XVII, como Velázquez, Ribera, o Caravaggio. Lo importante para él es el mensaje moralizante: "la utilidad de la pintura es más divina que otra alguna" (Pacheco, 1866: 173). Son acertados sus estudios anatómicos, aunque evita los desnudos, que los representa de espaldas o con paños de pureza. Los pechos desnudos solo aparecen en las figuras antropozoomórficas que portan el escudo de armas y en la Envidia, pero sin recrearse en estos atributos.

Se trata, por tanto, de una obra maestra del arte de la Sevilla del s. XVII, con un programa muy adecuado para iniciar a futuros historiadores del arte en las diversas metodologías como el análisis, identificación, interpretación y lectura. Muy útil para la aplicación de las diversas categorías estéticas. Pero además, es otro de los vehículos que permiten llegar al mejor conocimiento de la historia, cultura y sociedad de la España de los siglos XVI y XVII. 


\section{Referencias bibliográficas}

BROWN, Jonhatan (1988). Imágenes e ideas en la pintura española del siglo XVII. Alianza Forma: Madrid.

CAMÓN AZNAR, José (1978), "Escuela Sevillana”, en La pintura española del siglo XVII.

"SummaArtis, vol. XXV”, Espasa-Calpe, Madrid.

CARMONA MUELA, Juan (2010). Iconografía cristiana. Guía básica para estudiantes. Akal: Madrid.

FALCÓN MARTÍNEZ, Constantino, FERNÁNDEZ-GALIANO, Emilio y LÓPEZ MELERO, Rraquel (1990). Diccionario de mitología clásica 1 y 2. Alianza Editorial: Madrid. GIORDANO, Carlos y PALMISANO, Nicolás (coord.) (2011). Guía visual de la Casa de Pilatos. Dos de Arte Ediciones: Barcelona.

HUMBERT, Jean (1972). Mitología griega y romana. Gustavo Gili: Barcelona.

LLEÓ CAÑAL, Vicente (1998). La Casa de Pilatos. Electa España: Madrid.

MARÍAS, Fernando (1993). Diego Velázquez. El Arte y sus creadores. Historia 16: Madrid.

ORIA SEGURA, Mercedes (1997). Hércules en Hispania: una aproximación. Promociones y Publicaciones Universitarias: Barcelona.

PACHECO, Francisco (1866). Arte de la pintura, su antigüedad y grandezas. Edición de Gregorio Cruzada Villaamil, Imprenta de Manuel Galiano: Madrid.

PALOMINO, Antonio (1795). El Museo Pictórico y Escala Óptica. Imprenta de Sancha: Madrid.

RODRÍGUEZ SANTIDRIÁN, Pedro (2007). Lorenzo Valla, MarsilioFicino, AngeloPoliziano, Pico della Mirandola, Pietro Pomponazzi, BaldassareCastiglione, Francesco Guicciardini: Humanismo y Renacimiento. Alianza Editorial: Madrid.

RUIZ DE ELVIRA, Antonio (1984). Mitología clásica., Gredos: Madrid.

SCHLOSSER, Julius von (1976). La Literatura Artística. Manual de fuentes de la historia moderna del arte. Cátedra: Madrid.

SEBASTIÁN, Santiago (ed.) (1993). Alciato. Emblemas. Ediciones Akal: Madrid.

SEBASTIÁN, Santiago (1978). Arte y Humanismo. Cátedra: Madrid.

VAENIUS, Otto (1996), Quinti Horatii Flacci Emblemata (edición facsímil de la de Amberes, 1612), Universidad Europea-Cees Ediciones, Madrid.VASARI, Giorgio (2004). Las vidas de los más excelentes arquitectos, pintores y escultores italianos desde Cimabue a nuestros tiempos (Antología). Estudio, selección y traducción de María Teresa Méndez Baiges y Juan María Montijano García. Tecnos: Madrid. 